\title{
Clinical utility of ivabradine in cardiovascular disease management: current status
}

This article was published in the following Dove Press journal:

Research Reports in Clinical Cardiology

26 August 2014

Number of times this article has been viewed

\author{
Giuseppe MC Rosano ${ }^{1,2}$ \\ Cristiana Vitale ${ }^{1,2}$ \\ Ilaria Spoletini ${ }^{\prime}$ \\ Maurizio Volterrani' \\ 'Department of Medical Sciences, \\ IRCCS San Raffaele Pisana, Rome, \\ Italy; ${ }^{2}$ Cardiovascular and Cell \\ Sciences Research Institute, \\ St George's University of London, \\ London, UK
}

Correspondence: Giuseppe MC Rosano Centre for Clinical and Basic Research IRCCS San Raffaele Pisana, via della Pisana, 235, 00163 Rome, Italy

Tel +3906 52252409

Fax +39065225 2465

Email giuseppe.rosano@sanraffaele.it

\begin{abstract}
Ivabradine is a selective antagonist of the funny channels with anti-anginal and antiischemic properties, approved for the treatment of coronary artery disease (CAD) and heart failure (HF). It provides pure heart rate reduction, reducing the diastolic depolarization slope, without altering hemodynamic parameters. This review summarizes the current knowledge on the efficacy of ivabradine in patients with cardiovascular diseases, with a particular focus on its role in the clinical management of patients with CAD and HF. There is consistent evidence that ivabradine is effective in reducing angina pectoris symptoms and myocardial ischemia. At approved doses ivabradine is safe, improves exercise tolerance, and reduces heart rate. Available data from clinical trials support its use in the management of patients with stable CAD and chronic HF. Recent studies have cast doubt on the safety of non-approved high doses of ivabradine for the treatment of patients with CAD and without clinical HF, but have shown no concerns on the doses approved for clinical use.
\end{abstract}

Keywords: ivabradine, coronary artery disease, heart failure, angina pectoris, exercise performance

\section{Introduction}

Ivabradine is a relatively novel agent that has been approved, in 2005, by the European Medicines Agency (EMA) for the treatment of angina pectoris and myocardial ischemia in patients with coronary artery disease (CAD) intolerant to beta-blockers. Subsequently, the clinical indication of ivabradine has been extended for use in association with beta-blockers in patients with CAD and in patients with heart failure (HF). Ivabradine is the first funny channel [I(f)] inhibitor utilized in clinical practice. ${ }^{1}$ Unlike beta-blockers and calcium channel blockers, ivabradine acts by reducing the heart rate via selective and specific inhibition of the mixed sodium/potassium current in sino-atrial pacemaker nodal cells. ${ }^{2}$ In particular, by modulating the rate of spontaneous diastolic depolarization of sino-atrial myocytes, the I(f) inhibition induced by ivabradine prolongs the slow depolarization phase and therefore leads to a decrease in heart rate. This effect is devoid of any negative inotropic or dromotropic consequence. ${ }^{3-5}$ Here, we will review the available literature on the efficacy of ivabradine in patients with cardiovascular disease, with a particular focus on the implications of its clinical use.

\section{Efficacy of ivabradine in CAD and angina}

Due to its mechanism of action, ivabradine preserves cardiac contractility and relaxation, atrioventricular conduction and ventricular repolarization and, alike other only experimentally used selective bradycardic agents, ${ }^{6,7}$ reduces infarct size. ${ }^{8}$ 
Randomized clinical trials have shown that ivabradine is an effective anti-anginal and anti-ischemic agent, alone or in combination with beta-blockers.

The INITIATIVE (INternatIonal TrIal on the treATment of angina with Ivabradine Vs atEnolol) trial $^{9}$ was designed to compare the effects of ivabradine and a beta-blocker (atenolol) on cardiovascular outcomes. This 4 month, randomized, controlled, non-inferiority trial, investigated the effects of ivabradine with atenolol on exercise tolerance and ischemia in more than 900 patients with stable angina. A dose-dependent equivalent of ivabradine with atenolol was demonstrated in increasing total exercise duration, reducing angina frequency and the consumption of short-acting nitrates. Heart rate at rest and at peak of exercise was significantly decreased, and ivabradine was non-inferior to atenolol in total exercise capacity with a diminution in angina attacks, showing a relevant anti-ischemic effect. The study showed that the anti-ischemic effect of ivabradine was significantly greater than that of atenolol for a given heart rate reduction, suggesting that the similar reduction of heart rate with ivabradine or beta-blockers is expected to have different anti-ischemic effects.

As reviewed elsewhere,${ }^{10}$ there is evidence that ivabradine treatment leads to dose-dependent reduction in resting and exercise-induced heart rate, and therefore to decreased angina frequency. The ASSOCIATE (evaluation of the Antianginal efficacy and Safety of the aSsociation Of the If Current Inhibitor ivAbradine with a beTa-blockEr) study ${ }^{11}$ investigated whether the addition of ivabradine improved exercise capacity, objective markers of myocardial ischemia, and anginal symptoms in nearly 900 patients with chronic stable angina treated with atenolol. This randomized, double blind, placebo-controlled trial demonstrated that total exercise duration, time to angina onset, $1 \mathrm{~mm}$ ST segment depression, and limiting angina symptoms were all improved by the adjunct of ivabradine. This trial also showed that ivabradine was safe and effective for patients with chronic stable angina who were already taking atenolol.

The BEAUTIFUL (morBidity, mortality EvAlUaTion of the IF inhibitor ivabradine in patients with coronary disease and left-ventricULar dysfunction) trial $^{12}$ investigated the effect of ivabradine on cardiovascular outcomes in patients with stable CAD and left ventricular systolic dysfunction. In this trial, more than 10,000 patients were randomly assigned to receive ivabradine or placebo in addition to first-choice cardiovascular medication, including beta-blockers. The overall study showed a favorable effect of ivabradine on ischemic events in patients with a baseline heart rate of 70 beats per minute (bpm) or greater, with a reduction in the incidence of admission to hospital for myocardial infarction and coronary revascularization. ${ }^{13,14}$ The BEAUTIFUL echocardiographic sub study ${ }^{15}$ found a favorable effect of ivabradine versus placebo on left ventricular remodeling and function in patients with CAD and left ventricular systolic dysfunction. In particular, ivabradine was associated with a significant decrease in left ventricular end-systolic volume index and an increase in left ventricular ejection fraction. Reduction in left ventricular end-systolic volume index was related to the degree of heart rate reduction with ivabradine. This suggests that ivabradine may be able to reverse left ventricular remodeling. ${ }^{16}$ Also, a study ${ }^{17}$ showed that the ivabradine-induced heart rate reduction was less evident during sleep and that combination therapy with beta-blocker was well tolerated.

The effect of ivabradine was recently investigated in patients with acute ST-segment elevation myocardial infarction treated with primary percutaneous coronary intervention, by the VIVIFY (eValuation of the IntraVenous IF inhibitor ivabradine after st-segment elevation mYocardial infarction) study. ${ }^{18}$ This randomized, placebo-controlled, double-blind, pilot study indicates that the use of ivabradine after percutaneous coronary intervention for ST-segment elevation myocardial infarction produced a rapid and sustained reduction in heart rate. Such a rapid and reversible slowing of heart rate was not associated with changes in blood pressure. Also, intravenous ivabradine was safe and well tolerated. Potential beneficial effects of ivabradine against reperfusion injury ${ }^{8}$ were not studied, since ivabradine was not given at immediate reperfusion. Taken together, the available data show that ivabradine therapy improves exercise performance and delays the development of ischemia in patients with chronic stable angina who are or are not treated with beta-blockers.

Recently, the SIGNIFY (Study assessInG the morbiditymortality beNefits of the IF inhibitor ivabradine in patients with CAD) trial ${ }^{19}$ that evaluated the long-term effect of ivabradine in patients aged 55 years or older with stable CAD and left ventricular ejection fraction above $40 \%$, with no clinical sign of HF, reported some preliminary contradictory findings. The SIGNIFY tested the hypothesis that heart rate reduction with high dose (not approved by EMA) ivabradine may reduce mortality and cardiovascular events in patients with CAD. Preliminary results from the SIGNIFY showed a small but significant increase in the combined risk of cardiovascular death or non-fatal heart attack with ivabradine in a subgroup of patients with symptomatic angina (Canadian Cardiovascular Society class II-IV). For these reasons, in May 2014, the EMA has started a 
review of the benefit/risk ratio of ivabradine, after a request by the European Commission, based on the preliminary results of the SIGNIFY. The review will help understand the impact of these data on the balance of benefits and risks of ivabradine. The ongoing review of the SIGNIFY data by the EMA is expected to clarify the benefit/risk of ivabradine in patients with CAD. However, it must be clarified that SIGNIFY was conducted with a titration and a dose of the drug that is not approved for clinical use and therefore the results of the trial have little implication for clinical practice. These preliminary data do suggest, however, that ivabradine up-titration should be performed according to the approved regimens and that maximum recommended doses must not be exceeded.

\section{Efficacy of ivabradine in heart failure}

Studies with beta-blockers have shown that the beneficial effect of these drugs in patients with HF is related to their degree of heart rate reduction. ${ }^{20,21}$ The BEAUTIFUL study showed that, in patients with left ventricular dysfunction and heart rate $>70 \mathrm{bpm}$, ivabradine reduced cardiovascular events. Therefore, a sound rationale supported the investigation of ivabradine in patients with chronic HF due to left ventricular systolic dysfunction. The SHIFT (Systolic Heart failure treatment with the IF inhibitor ivabradine Trial) ${ }^{22}$ tested the effect of ivabradine as add-on to standard treatment with angiotensin converting enzyme (ACE)-inhibitors and beta-blockers in patients with chronic HF in sinus rhythm. The trial showed a significant effect of ivabradine on cardiovascular and total mortality and hospitalization for HF. Of interest, the trial showed a progressive protective effect of ivabradine on cardiovascular death and hospital admission for worsening HF, with reductions in heart rate. Best event-free survival was observed in patients with heart rate $>60 \mathrm{bpm}$. Also, decrease in heart rate was associated with a reduction in cardiovascular death and hospital admission for worsening HF. The SHIFT echocardiography sub study ${ }^{23}$ confirmed the efficacy of ivabradine on left ventricular remodeling and ejection function, and a subsequent analysis ${ }^{24}$ further showed that the benefit obtained with ivabradine treatment on HF hospitalization in the SHIFT was maintained over several years and attenuated the likelihood of recurrent hospitalizations for worsening HF, also with a reduction in health care costs.

In a subsequent post hoc analysis of the SHIFT requested by the EMA, ${ }^{25}$ in patients with heart rate $\geq 75 \mathrm{bpm}$, ivabradine was shown to reduce all-cause mortality (17\% risk reduction), therefore suggesting that the higher the baseline heart rate the greater the effect of the drug. Ivabradine was effective in reducing cardiovascular death or HF hospitalization, all-cause death, HF death, and hospitalization for worsening HF irrespective of disease severity. Based on these data, the EMA recommends prescription of ivabradine for patients with chronic HF of New York Heart Association classes II-IV, with systolic dysfunction, in sinus rhythm, and with heart rate $\geq 75 \mathrm{bpm}$, in combination with standard therapy including a beta-blocker or when betablocker therapy is contraindicated or not tolerated.

Although the BEAUTIFUL and the SHIFT trials included a population that differed in their primary diagnosis (in particular, for the presence of HF), a pooled analysis of individual patient data from the two trials was conducted, ${ }^{26}$ which further demonstrated the effect of ivabradine in patients with left ventricular systolic dysfunction.

Of note, in the Patient-Reported Outcomes sub study, ${ }^{27}$ the reduction of heart rate obtained after ivabradine treatment was associated with an improvement in health-related quality of life. As a consequence, improved wellbeing may be reflected in improved survival, as the former is a predictor of long-term mortality in $\mathrm{HF}^{28}$ Thus, given the relevance of quality of life and functional capacity in HF, the CARVIVA HF (CARVedilol, IVAbradine or their combination on exercise capacity in patients with Heart Failure) trial ${ }^{29}$ assessed the effect of ivabradine on exercise capacity, exercise duration, and quality of life of a therapeutic strategy aimed at optimizing ACE inhibition and reducing heart rate using carvedilol, ivabradine, or their combination. This prospective, randomized, open, blinded end-point study in patients with chronic HF demonstrated that ivabradine alone or in combination with carvedilol was more effective than carvedilol alone in improving exercise capacity and quality of life in HF patients. Also, patients receiving ivabradine plus carvedilol were more likely to reach target therapeutic doses than patients receiving carvedilol alone. Ivabradine was found to be an effective add-on treatment to ACE inhibitors and diuretics in HF, allowing uptitration of ACE inhibitors to optimal doses in HF. These results also suggest that the effect of ivabradine on exercise capacity was related not only to heart rate reduction, but also to differing effects of ivabradine and carvedilol on skeletal muscle performance.

\section{Clinical implications and mechanisms of action of ivabradine}

Treatment with ivabradine reduces resting heart rate, heart rate during exercise, and rate-pressure product (heart rate $x$ systolic blood pressure) without affecting resting and exercise blood pressure. These effects result in a reduction in cardiac 
workload and myocardial oxygen consumption at rest and during exercise that may benefit patients with ischemic heart disease as well as those with $\mathrm{HF}^{30}$

In patients with ischemic heart disease a significant and dose-dependent improvement in total exercise capacity, as well as a significant decrease in the number of anginal episodes and use of short-acting nitrates, has been observed with ivabradine. ${ }^{30}$ However, the pharmacologic management of patients affected by angina remains challenging as the addition of ivabradine should be considered in symptom-limited patients when heart rate is sub optimally controlled. ${ }^{10}$ In particular, ivabradine is indicated for the symptomatic treatment of chronic stable angina pectoris in patients with normal sinus rhythm, unable to tolerate or with a contraindication to the use of beta-blockers, or in combination with beta-blockers, whose heart rate is higher than $60 \mathrm{bpm}$. Given the results of the SIGNIFY it is advisable not to exceed the recommended doses of 5 or $7.5 \mathrm{mg}$ twice daily and to start slow in the elderly where the initial dose should be $2.5 \mathrm{mg}$ twice daily. The dose should be adjusted according to the pharmacodynamic effect on heart rate. Ivabradine should not be seen as an alternative to beta-blockers but rather a treatment to use in association with beta-blockers to maximize the anti-ischemic effect of heart rate reduction as shown by the ASSOCIATE study.

Ivabradine is a valid therapeutic resource for HF with proven long-term benefits. ${ }^{31}$ The European Society of Cardiology/Heart Failure Association guidelines suggest its use in patients already receiving an ACE-inhibitor, a betablocker and, if indicated and tolerated a mineralocorticoid receptor antagonist, in sinus rhythm when the heart rate is $>70 \mathrm{bpm}$. The EMA suggests introducing it in therapy when the heart rate is $>75 \mathrm{bpm}$. The first recommendation is evidence-based and takes into account the results on the cumulative end points of the SHIFT study (Mortality and Hospital Admission) while the EMA recommendation is based on the heart rate threshold above which the drug showed a benefit on overall mortality. Regardless of these differences, ivabradine is extremely effective in improving quality of life and exercise capacity with long-term benefits and should be implemented whenever possible in patients with HF.

\section{Side effects and benefit/risk ratio of ivabradine}

The most commonly reported side effects are bradycardia and visual symptoms (phosphenes, or flashing scotomata), ${ }^{32}$ which are usually temporary and disappear after the drug is stopped. Visual symptoms may appear because some retinal cells also harbor the I(f) current.
On the other hand, as aforementioned, ivabradine has no negative effect on inotropy, does not lead to coronary vasoconstriction, and has no effect on blood pressure. ${ }^{33}$ Finally, ivabradine shows excellent tolerability and safety also when added to other anti-anginal agents. ${ }^{18}$ The clinical development plan of ivabradine has shown that the drug, at the approved doses, is effective and safe and has a positive benefit/risk ratio in ischemic heart disease and in HF. In patients with angina, however, recent data from the SIGNIFY study seem to suggest that high dose and fast uptitration may be associated with increased event rates and therefore should be avoided.

\section{Conclusion}

Ivabradine is a heart rate reducing agent with added benefits on coronary and peripheral circulation and well-established anti-anginal properties. It is recommended for the treatment of CAD and HF. Short and medium term studies support the use of ivabradine in patients with ischemic heart disease according to the approved doses. However, its benefit/risk ratio is currently under review by the EMA based on the preliminary negative findings from a subgroup of patients of the SIGNIFY trial that tested high dose and fast uptitration of the drug. Future approval by the Food and Drug Administration in the US is also warranted.

The place in therapy of ivabradine in HF is well established and is supported by the evidence of its effect on mortality and hospitalization for HF.

\section{Disclosure}

The authors declare that they have no conflicts of interest.

\section{References}

1. Sulfi $\mathrm{S}$, Timmis AD. Ivabradine - the first selective sinus node I(f) channel inhibitor in the treatment of stable angina. Int $J$ Clin Pract. 2006;60(2):222-228.

2. Tardif JC. Ivabradine: I(f) inhibition in the management of stable angina pectoris and other cardiovascular diseases. Drugs Today (Barc). 2008;44(3):171-181.

3. DiFrancesco D. Funny channels in the control of cardiac rhythm and mode of action of selective blockers. Pharmacol Res. 2006;53(5):399-406.

4. Heusch G. Pleiotropic action(s) of the bradycardic agent ivabradine: cardiovascular protection beyond heart rate reduction. BrJ Pharmacol. 2008;155(7):970-971.

5. Heusch G. Heart rate in the pathophysiology of coronary blood flow and myocardial ischaemia: benefit from selective bradycardic agents. $\mathrm{Br} J$ Pharmacol. 2008;153(8):1589-1601.

6. Guth BD, Heusch G, Seitelberger R, Ross J Jr. Elimination of exerciseinduced regional myocardial dysfunction by a bradycardiac agent in dogs with chronic coronary stenosis. Circulation. 1987;75(3):661-669.

7. Schulz R, Rose J, Skyschally A, Heusch G. Bradycardic agent UL-FS 49 attenuates ischemic regional myocardial dysfunction and reduces infarct size in swine: comparison with the beta-blocker atenolol. $J$ Cardiovasc Pharmacol. 1995;25(2):216-228. 
8. Heusch G, Skyschally A, Gres P, van Caster P, Schilawa D, Schulz R. Improvement of regional myocardial blood flow and function and reduction of infarct size with ivabradine: protection beyond heart rate reduction. Eur Heart J. 2008;29(18):2265-2275.

9. Tardif JC, Ford I, Tendera M, Bourassa MG, Fox K, INITIATIVE Investigators. Efficacy of ivabradine, a new selective I(f) inhibitor, compared with atenolol in patients with chronic stable angina. Eur Heart J. 2005;26(23):2529-2536.

10. de Silva R, Fox KM. Angina: Ivabradine for treatment of stable angina pectoris. Nat Rev Cardiol. 2009;6(5):329-330.

11. Tardif JC, Ponikowski P, Kahan T, ASSOCIATE Study Investigators. Efficacy of the I(f) current inhibitor ivabradine in patients with chronic stable angina receiving beta-blocker therapy: a 4-month, randomized, placebo-controlled trial. Eur Heart J. 2009;30(5):540-548.

12. Fox K, Ford I, Steg PG, Tendera M, Ferrari R, BEAUTIFUL Investigators. Ivabradine for patients with stable coronary artery disease and leftventricular systolic dysfunction (BEAUTIFUL): a randomised, doubleblind, placebo-controlled trial. Lancet. 2008;372(9641):807-816.

13. Heusch G. A BEAUTIFUL lesson - ivabradine protects from ischaemia, but not from heart failure: through heart rate reduction or more? Eur Heart J. 2009;30(19):2300-2301.

14. Fox K, Ford I, Steg PG, et al. Relationship between ivabradine treatment and cardiovascular outcomes in patients with stable coronary artery disease and left ventricular systolic dysfunction with limiting angina: a subgroup analysis of the randomized, controlled BEAUTIFUL trial. Eur Heart J. 2009;30(19):2337-2345.

15. Ceconi C, Freedman SB, Tardif JC, et al. Effect of heart rate reduction by ivabradine on left ventricular remodeling in the echocardiographic substudy of BEAUTIFUL. Int J Cardiol. 2011;146(3):408-414

16. Heusch G, Libby P, Gersh B, et al. Cardiovascular remodelling in coronary artery disease and heart failure. Lancet. 2014;383(9932):1933-1943.

17. Tendera M, Talajic M, Robertson M, et al. Safety of ivabradine in patients with coronary artery disease and left ventricular systolic dysfunction (from the BEAUTIFUL Holter Substudy). Am J Cardiol. 2011;107(6):805-811.

18. Steg P, Lopez-de-Sa E, Schiele F, et al. Safety of intravenous ivabradine in acute ST-segment elevation myocardial infarction patients treated with primary percutaneous coronary intervention: a randomized, placebo-controlled, double-blind, pilot study. Eur Heart J Acute Cardiovasc Care. 2013;2(3):270-279.

19. Fox K, Ford I, Steg PG, Tardif JC, Tendera M, Ferrari R. Rationale, design, and baseline characteristics of the Study assessInG the morbidity-mortality beNefits of the If inhibitor ivabradine in patients with coronarY artery disease (SIGNIFY trial): a randomized, doubleblind, placebo-controlled trial of ivabradine in patients with stable coronary artery disease without clinical heart failure. Am Heart J. 2013;166(4):654-661.
20. McAlister FA, Wiebe N, Ezekowitz JA, Leung AA, Armstrong PW. Meta-analysis: beta-blocker dose, heart rate reduction, and death in patients with heart failure. Ann Intern Med. 2009;150(11):784-794.

21. Heusch G. Heart rate and heart failure. Not a simple relationship. Circ J. 2011;75(2):229-236.

22. Swedberg K, Komajda M, Bohm M, et al. Ivabradine and outcomes in chronic heart failure (SHIFT): a randomised placebo-controlled study. Lancet. 2010;376(9744):875-885.

23. Tardif JC, O'Meara E, Komajda M, et al. Effects of selective heart rate reduction with ivabradine on left ventricular remodelling and function: results from the SHIFT echocardiography substudy. Eur Heart $J$. 2011;32(20):2507-2515.

24. Borer JS, Bohm M, Ford I, et al. Effect of ivabradine on recurrent hospitalization for worsening heart failure in patients with chronic systolic heart failure: the SHIFT Study. Eur Heart $J$. 2012;33(22):2813-2820.

25. Bohm M, Borer J, Ford I, et al. Heart rate at baseline influences the effect of ivabradine on cardiovascular outcomes in chronic heart failure: analysis from the SHIFT study. Clin Res Cardiol. 2013;102(1): $11-22$.

26. Fox K, Komajda M, Ford I, et al. Effect of ivabradine in patients with left-ventricular systolic dysfunction: a pooled analysis of individual patient data from the BEAUTIFUL and SHIFT trials. Eur Heart $J$. 2013;34(29):2263-2270.

27. Ekman I, Chassany O, Komajda M, et al. Heart rate reduction with ivabradine and health related quality of life in patients with chronic heart failure: results from the SHIFT study. Eur Heart J. 2011;32(19): 2395-2404.

28. Zuluaga MC, Guallar-Castillon P, Lopez-Garcia E, et al. Generic and disease-specific quality of life as a predictor of long-term mortality in heart failure. Eur J Heart Fail. 2010;12(12):1372-1378.

29. Volterrani M, Cice G, Caminiti G, et al. Effect of Carvedilol, Ivabradine or their combination on exercise capacity in patients with Heart Failure (the CARVIVA HF trial). Int J Cardiol. 2011;151(2):218-224.

30. Borer JS, Fox K, Jaillon P, Lerebours G, Ivabradine Investigators Group. Antianginal and antiischemic effects of ivabradine, an I(f) inhibitor, in stable angina: a randomized, double-blind, multicentered, placebocontrolled trial. Circulation. 2003;107(6):817-823.

31. Rosa GM, Ferrero S, Ghione P, Valbusa A, Brunelli C. An evaluation of the pharmacokinetics and pharmacodynamics of ivabradine for the treatment of heart failure. Expert Opin Drug Metab Toxicol. 2014;10(2): 279-291.

32. Savelieva I, Camm AJ. I f inhibition with ivabradine: electrophysiological effects and safety. Drug Saf. 2008;31(2):95-107.

33. Rosano GM, Vitale C, Volterrani M. Heart rate in ischemic heart disease The innovation of ivabradine: more than pure heart rate reduction. Adv Ther. 2010;27(4):202-210.
Research Reports in Clinical Cardiology

\section{Publish your work in this journal}

Research Reports in Clinical Cardiology is an international, peerreviewed, open access journal publishing original research, reports, editorials, reviews and commentaries on all areas of cardiology in the clinic and laboratory. The manuscript management system is com pletely online and includes a very quick and fair peer-review system.

\section{Dovepress}

Visit http://www.dovepress.com/testimonials.php to read real quotes from published authors. 